\title{
A role for the extended amygdala in the fear-enhancing effects of acute selective serotonin reuptake inhibitor treatment
}

\author{
S Ravinder ${ }^{1,4}$, NS Burghardt ${ }^{2,4}$, R Brodsky ${ }^{3}$, EP Bauer ${ }^{3}$ and S Chattarji ${ }^{1}$
}

Selective serotonin reuptake inhibitors (SSRIs) are reported to exacerbate symptoms of anxiety when treatment is initiated. These clinical findings have been extended to animal models wherein SSRIs also potentiate anxiety and fear learning, which depend on the amygdala. Yet, little is known about the role of specific amygdalar circuits in these acute effects of SSRIs. Here, we first confirmed that a single injection of fluoxetine $1 \mathrm{~h}$ before auditory fear conditioning potentiated fear memory in rats. To probe the neural substrates underlying this enhancement, we analyzed the expression patterns of the immediate early gene, Arc (activity-regulated cytoskeleton-associated protein). Consistent with previous reports, fear conditioning induced Arc protein expression in the lateral and basal amygdala. However, this was not enhanced further by pre-treatment with fluoxetine. Instead, fluoxetine significantly enhanced expression of Arc in the central amygdala $(\mathrm{CeA})$ and the bed nucleus of the stria terminalis (BNST). Next, we tested whether direct targeted infusions of fluoxetine into the CeA, or BNST, leads to the same fear-potentiating effect. Strikingly, direct infusion of fluoxetine into the BNST, but not the CeA, was sufficient to enhance fear memory. Moreover, this behavioral effect was also accompanied by robust Arc expression in the CeA, similar to the systemic injection. Our results identify a novel role for the BNST in the acute fear-enhancing effects of SSRIs. These findings highlight the need to look beyond the traditional focus on input nuclei of the amygdala and add to accumulating evidence implicating these microcircuits in gating fear and anxiety.

Translational Psychiatry (2013) 3, e209; doi:10.1038/tp.2012.137; published online 15 January 2013

\section{Introduction}

Antidepressant drugs, such as selective serotonin reuptake inhibitors (SSRIs), are commonly administered for treating a range of anxiety disorders. ${ }^{1-4}$ Although long-term treatment with SSRIs yields therapeutic benefits, they exacerbate symptoms of anxiety when treatment is initiated, potentially leading to an increased risk of suicidal ideation. ${ }^{5-10}$ Although the acute anxiogenic effects of SSRIs have been demonstrated in numerous rodent models of anxiety-like behavior, ${ }^{11-15}$ the cellular substrates of these acute effects are largely unknown.

Acute SSRI treatment, before auditory fear conditioning, leads to stronger fear memory, ${ }^{16}$ which is consistent with its known anxiogenic effects. Auditory fear conditioning offers a significant advantage as a robust model of associative emotional learning, as the neural circuitry and molecular mechanisms have been elucidated in detail in the amygdala. ${ }^{17-20}$ The lateral nucleus of the amygdala (LA) serves as the major input interface receiving sensory information from the thalamus and cortex. ${ }^{21,22}$ Information processed within the LA and basal nucleus of the amygdala (BA) is then relayed to output structures. The central nucleus of the amygdala (CeA) and the bed nucleus of the stria terminalis (BNST), which together comprise the extended amygdala, serve as the principal output structures of the amygdaloid complex that project to the brainstem and hypothalamus and mediate the expression of fear responses. ${ }^{23,24}$ While the CeA mediates expression of conditioned fear responses to brief stimuli, the BNST mediates generalized and sustained fear responses to more diffuse stimulus contingencies. ${ }^{25,26}$

Current understanding of the cellular and circuit mechanisms of fear conditioning gives rise to several predictions about how acute treatment with SSRIs may enhance fear memory. Plasticity in the LA is crucial for the formation of conditioned fear memory. ${ }^{20}$ Activity-regulated cytoskeleton-associated protein (Arc), a plasticity-related immediate early gene (IEG), is induced by auditory fear conditioning, in the LA and BA, and is essential for fear memory expression. ${ }^{27}$ Thus, SSRIs may potentiate fear memory by enhancing Arc expression in the LA or BA. Alternatively, SSRIs may affect the output nuclei, which have also been implicated in fear memory formation. ${ }^{19,28,29}$ In this study, we explore these possibilities by combining auditory fear conditioning, systemic treatment and targeted infusions of the SSRI fluoxetine into the amygdala and analysis of Arc expression patterns to identify components of the amygdalar fear circuitry that may underlie the acute behavioral effects of SSRIs.

\footnotetext{
${ }^{1}$ National Centre for Biological Sciences, Tata Institute of Fundamental Research, Bangalore, India; ${ }^{2}$ Departments of Neuroscience, Psychiatry \& Pharmacology, Columbia University, New York, NY, USA and ${ }^{3}$ Biology Department, Barnard College, Columbia University, New York, NY, USA

Correspondence: Dr S Chattarji, National Centre for Biological Sciences, GKVK Campus, Bellary Road, Bangalore 560065, India.

E-mail: shona@ncbs.res.in

${ }^{4}$ SR and NSB share first authorship.

Keywords: anxiety; bed nucleus of the stria terminalis; central amygdale; fear conditioning; fluoxetine; immediate early gene

Received 23 August 2012; revised 27 October 2012; accepted 10 November 2012
} 


\section{Materials and methods}

Subjects. Male Sprague-Dawley rats (250-300 g) were housed in groups of two or three with ad libitum access to food and water. All animal experiments were conducted at the National Centre for Biological Sciences (NCBS) with the exception of experiments involving local drug infusions, which were carried out at the animal facility at Barnard College. Animals were maintained in a temperature-controlled room, with a 14/10-h day/night cycle at NCBS and 12/ 12-h day/night cycle at the Barnard College animal facility. All procedures were approved by the Institutional Animal Ethics Committee for NCBS or Columbia University's Animal Care and Use Committee.

Drug administration. Fluoxetine hydrochloride was obtained from Hikal Ltd (Bangalore, India) and Sigma-Aldrich (St Louis, MO, USA).

Systemic injections. For systemic drug administration, fluoxetine was dissolved in $0.9 \%$ sterile saline and injected intraperitoneally (i.p.) at a dose of $10 \mathrm{mg} \mathrm{kg}^{-1} .28-30$

Local drug infusions. Cannulae were surgically implanted to locally infuse fluoxetine or saline into the CeA or BNST. Rats were anesthetized and maintained in deep anesthesia with a mixture of isoflurane and oxygen and placed in a stereotaxic apparatus. Body temperature was maintained with a heated gel pad. Betadine was applied to the scalp and a local anesthetic (bupivicaine, subcutaneous) was injected under the scalp. The skull was exposed, and small holes were drilled. Stainless steel guide cannulae (22 gauge; Plastics One, Roanoke, VA, USA) fitted with infusion cannulae (28 gauge) that extended $(2 \mathrm{~mm})$ beyond the base of the guide were positioned bilaterally above the $\mathrm{CeA}$ $(-2.5 \mathrm{~mm}$ anteroposterior $(\mathrm{AP}),+/-4.3 \mathrm{~mm}$ mediolateral (ML), $-8.0 \mathrm{~mm}$ dorsoventral (DV)) or BNST $(-0.6 \mathrm{~mm} \mathrm{AP}$, $+/-1.5 \mathrm{ML},-6.5 \mathrm{~mm} \mathrm{DV}) .{ }^{31}$ The guide cannulae were secured to the skull using surgical screws and acrylic dental cement. Infusion cannulae were replaced with dummy cannulae that did not extend beyond the guide cannulae to prevent clogging. After surgery, rats received an analgesic (carprofen, $5 \mathrm{mg} \mathrm{kg}^{-1}$, i.p.) and $5 \mathrm{ml}$ of lactated ringer (subcutaneous) and recovered for 1 week before drug infusion and behavioral testing.

Fluoxetine was infused into the CeA or BNST at a dose of 6 or $9 \mu \mathrm{g}$ per side (in $0.5 \mu \mathrm{l}$ saline). This choice of dose was based on the behavioral effects reported by earlier studies that have infused fluoxetine directly into the brain at these doses. $^{32,33}$ The drug solution was infused at a rate of $2 \mu \mathrm{min}^{-1}$ through infusion cannulae attached to a $1-\mu \mathrm{l}$ Hamilton syringe via polyethylene tubing. The cannulae were left in place for an additional $2 \mathrm{~min}$ after the infusion to allow for diffusion of the solution away from the cannula tip, after which the dummy cannulae were replaced and the rat was returned to its home cage.

To verify the placement of the injection cannula tips after behavioral testing, rats were anesthetized with Euthasol (containing pentobarbital; $100 \mathrm{mg} \mathrm{kg}^{-1}$, i.p.) and transcardially perfused with $0.9 \%$ saline followed by ice-cold
$4 \%$ paraformaldehyde in phosphate-buffered saline (PBS). Brains were removed and stored in $4 \%$ paraformaldehyde for $24 \mathrm{~h}$ and then cryoprotected in $20 \%$ followed by $30 \%$ sucrose (in $0.1 \mathrm{~m}$ phosphate buffer, $\mathrm{pH} 7.4$ ). Subsequently, brains were blocked and cut in $60 \mu \mathrm{m}$ sections through the CeA or BNST using a cryostat. After standard histological Nissl or hematoxylin staining, sections were examined on a light microscope to localize the cannula tip.

\section{Behavioral procedures}

Apparatus and stimuli. Rats were fear conditioned in chambers made of aluminium and Plexiglass walls with stainless steel rod flooring attached to a shock generator (Coulbourn Instruments, Allentown, PA, USA). The chamber was illuminated by an overhead yellow light, all of which was located within a sound attenuating box (Coulbourn Instruments). The testing context was made distinct by changing the walls, floors, lighting and introducing a peppermint odor to the chamber. A video camera was used to record behavioral conditioning and testing sessions for subsequent offline analysis. Stimulus presentation was controlled by a computer with Graphic State 2 software (Coulbourn Instruments). The conditioning and testing chambers were thoroughly cleaned with alcohol between sessions.

Fear conditioning. For experiments involving systemic drug administration, auditory fear conditioning consisted of a 3day procedure. On day 1, all rats were first habituated to the conditioning chamber followed by the testing chamber for $10 \mathrm{~min}$. On day 2, rats were injected with fluoxetine or saline, and 60 min later they were fear conditioned in the conditioning chamber. Fear conditioning involved five pairings of a conditioned stimulus (CS; $5 \mathrm{kHz}$ tone, $75 \mathrm{db}, 20 \mathrm{~s}$ ) that coterminated with an unconditioned stimulus $(0.5 \mathrm{~mA}$ footshock, $0.5 \mathrm{~s})$. The inter-trial interval varied randomly between 60 and 120 s. On day 3, rats were placed in the testing chamber where they received three CS presentations with an inter-trial interval that varied randomly between 60 and $120 \mathrm{~s}$. Behavior during the conditioning and testing sessions was videotaped for subsequent manual off-line analysis of freezing behavior. Freezing, defined as cessation of all movement except for respiration, was used as a measure of conditioned fear. Freezing is reported as a percentage of total tone presentation time.

For the local drug infusion experiments, rats were allowed to recover for 1 week after the surgery. On day 1 , rats were habituated to the conditioning chamber for $20 \mathrm{~min}$. On day 2 , rats were infused with fluoxetine or saline $15 \mathrm{~min}$ before they were fear conditioned with two pairings of the $\mathrm{CS}(5 \mathrm{kHz}$ tone, $75 \mathrm{db}, 30 \mathrm{~s})$ and unconditioned stimulus $(0.5 \mathrm{~mA}$ footshock, $0.5 \mathrm{~s})$. On day 3 , they were tested in the testing chamber with 10 CS presentations.

Immunohistochemistry. Two hours after the conditioning session, rats were killed and their brains were analyzed for behaviorally induced Arc protein expression. The 2-h time point after fear conditioning was chosen to examine Arc expression based on an earlier study that reported an induction of Arc protein expression in the LA and BA $2 \mathrm{~h}$ after fear conditioning. ${ }^{27}$ Rats were deeply anesthetized with 
a
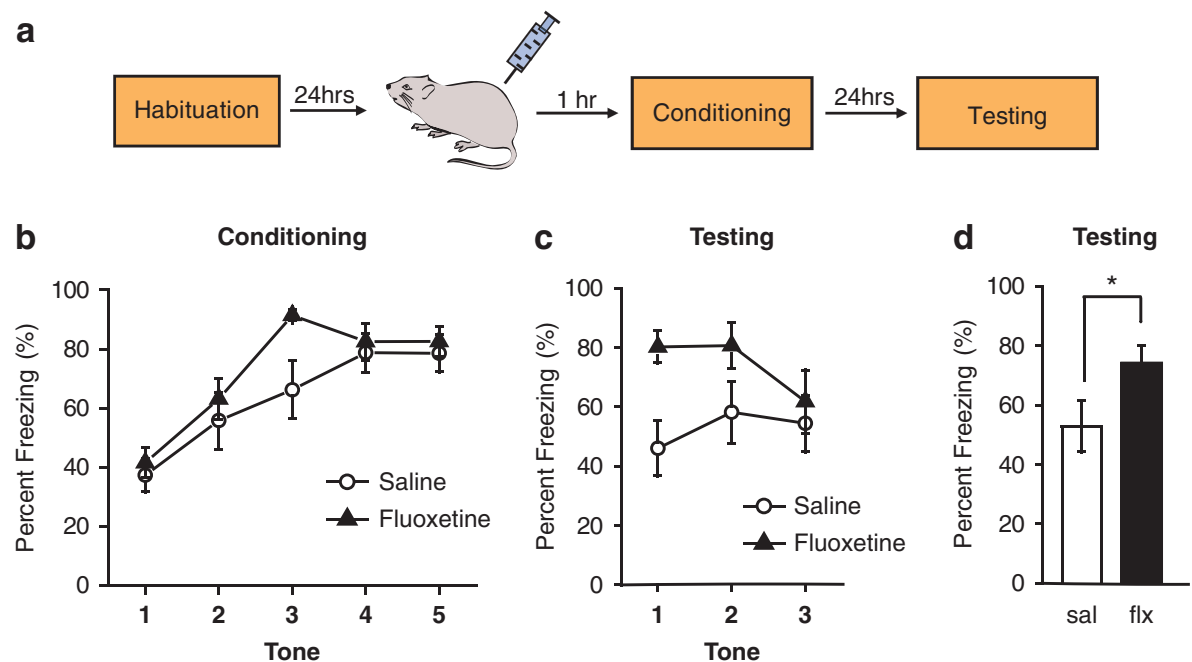

Figure 1 Acute systemic administration of fluoxetine enhances conditioned fear memory. (a) Schematic representation of the experimental protocol. Rats were habituated to the conditioning and testing context and injected with saline or fluoxetine $\left(10 \mathrm{mg} \mathrm{kg}^{-1}\right.$, i.p.) on the following day. One hour after injection, they were conditioned with five conditioned stimulus-unconditioned stimulus (CS-US) pairings and tested for conditioned fear to three CS presentations on the following day. (b) Percentage of time spent freezing in response to tone presentations on the conditioning day. (c) Percentage of time spent freezing in response to tone presentations on the testing day. (d) Percentage of time spent freezing to all three tones on the testing day. Saline (sal): $N=13$, fluoxetine (flx): $N=14$. Error bars indicate mean \pm s.e.m. and ${ }^{*} P<0.05$.

halothane followed by ketamine $(0.05 \mathrm{ml}$ per $100 \mathrm{~g}$, i.p.) and xylazine $(0.2 \mathrm{ml}$ per $100 \mathrm{~g}$, i.p.) and transcardially perfused with $0.1 \mathrm{M}$ PBS, followed by ice-cold $4 \%$ paraformaldehydePBS. Brains were removed and postfixed in $4 \%$ paraformaldehyde-PBS for $24 \mathrm{~h}$ and then cryoprotected in $20 \%$ followed by $30 \%$ sucrose (in $0.1 \mathrm{~m}$ phosphate buffer, $\mathrm{pH}$ 7.4). A cryostat was used to cut $40-\mu \mathrm{m}$ thick coronal brain sections containing the amygdala. Every sixth section was then processed for Arc immunoreactivity. After blocking in PBS containing $1 \%$ bovine serum albumin (BSA Fraction $\mathrm{V}$, Sigma-Aldrich)- $0.1 \%$ Triton $\mathrm{X}-100$, slices were incubated overnight at room temperature in anti-Arc primary antibody (mouse monoclonal, 1:1000 dilution; Santa Cruz Biotechnology, Santa Cruz, CA, USA) in PBS-1\% BSA-0.1\% Triton $X-100$. Sections were then incubated with a biotinylated secondary antibody (anti-mouse IgG, 1:200 dilution, Vectastain Elite ABC kit, Vector Laboratories, Burlingame, CA, USA) for $1 \mathrm{~h}$ at room temperature. Arc-expressing cells were then visualized using VectaStain Elite $A B C$ kit (Vector Laboratories) followed by DAB staining (DAB peroxidase substrate, Vector Laboratories). Sections were then mounted onto Fisherbrand electrostatic slides. Sections from comparable anterior-posterior levels were selected for scoring $(-2.04$ to $-2.92 \mathrm{~mm}$ posterior to Bregma for the CeA, 0.36 to $-0.96 \mathrm{~mm}$ posterior to Bregma for the BNST and -2.92 and $-3.96 \mathrm{~mm}$ posterior to Bregma for the dentate gyrus (DG)). Cell counts were taken from at least three sections (six hemispheres) per rat. Cells were counted manually using the NeuroLucida image analysis system (MicroBrightField, Wiliston, VT, USA) attached to an Olympus BX61 microscope (Olympus, Tokyo, Japan; $\times 40,0.75$ numerical aperture).

Statistics. Statistical analysis was performed using OriginPro-8 (OriginLab, Northampton, MA, USA) or SPSS-9 (SPSS Inc., Chicago, IL, USA). Fear conditioning data were analyzed using a repeated measures analysis of variance (ANOVA) for tone-wise freezing scores (within subject factor-tone presentation, between subject factordrug treatment). Student's $t$-test was used to compare freezing scores averaged across the first three tones. Arc protein expression was analyzed separately in the LA, BA, CeA, BNST and DG using a two-way ANOVA (between subject factors-fear conditioning and drug treatment) or Student's $t$-test for independent samples, where applicable. Significance was accepted for $P<0.05$.

\section{Results}

Acute systemic administration of fluoxetine enhances conditioned fear memory. We first tested the effects of the SSRI fluoxetine on Pavlovian auditory fear conditioning, an amygdala-dependent form of fear learning in which an animal rapidly learns to associate a previously innocuous tone with an aversive footshock. Re-exposure to the tone alone elicits a conditioned response, such as cessation of locomotor activity or 'freezing', which we used as a behavioral measure for the learned association. Rats were administered a single injection of fluoxetine $\left(10 \mathrm{mg} \mathrm{kg}^{-1}\right.$, i.p.) or saline $1 \mathrm{~h}$ before fear conditioning (Figure 1a). We found that fluoxetine did not significantly change freezing during the conditioning session when all tones were included in the analysis (Figure $1 \mathrm{~b}$; repeated measures ANOVA: $\left.F_{(1,25)}=2.73, P=0.11\right)$. However, we did find that fluoxetine-treated rats exhibited higher freezing than saline-treated rats to the third tone $\left(t_{(12.96)}=2.46, P<0.05\right)$, consistent with previous studies showing an enhancement in learning following acute SSRI administration. ${ }^{16}$ Thus, there is a possibility that in our experiment, the fluoxetine group learned fear faster but then approached maximal levels of freezing faster. Interestingly, presentation of the tone alone the next day during the testing session elicited significantly higher freezing in fluoxetine- 
a

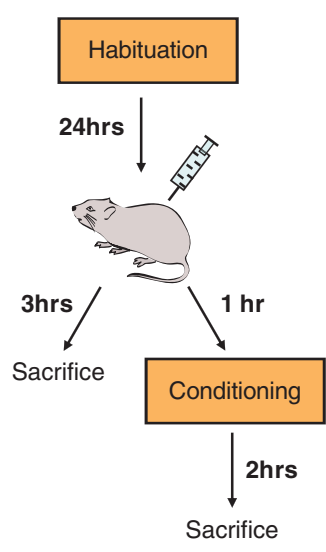

b
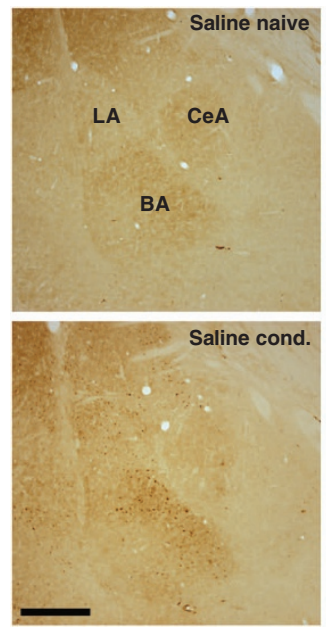

BA

e
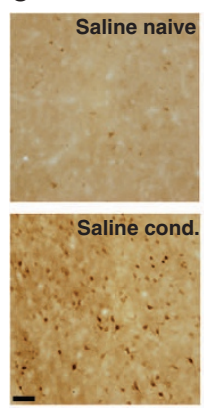

f

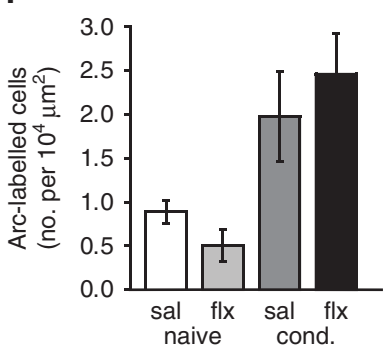

LA d
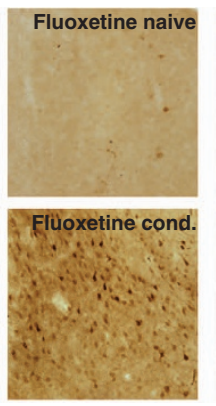

g

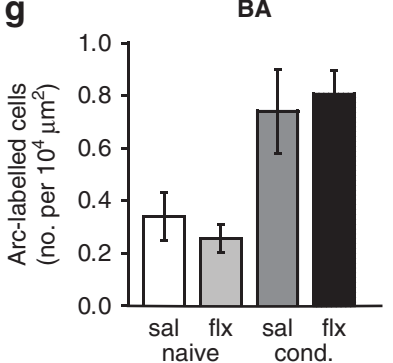

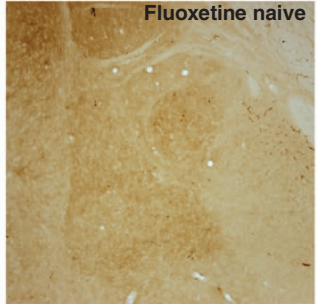

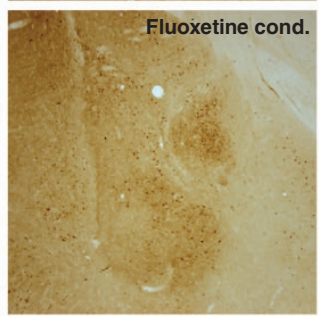

CeA
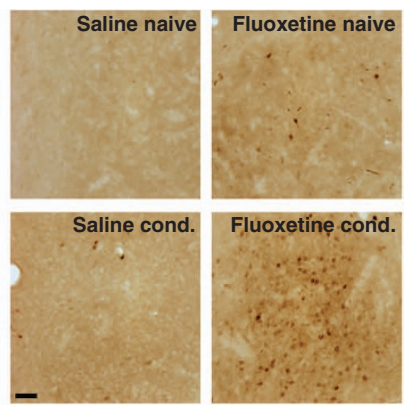

h

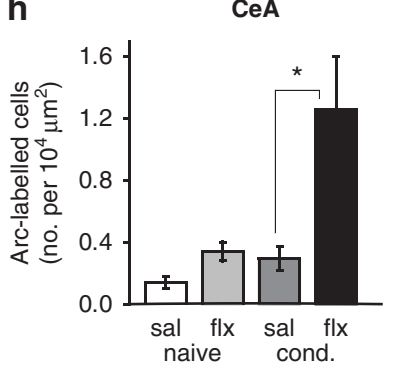

Figure 2 Acute systemic fluoxetine treatment before fear conditioning leads to an increase in Arc (activity-regulated cytoskeleton-associated protein) expression in the central nucleus $(\mathrm{CeA})$, but not lateral $(\mathrm{LA})$ or basal nucleus $(\mathrm{BA})$ of the amygdala. (a) Schematic representation of the experimental protocol. Rats were habituated to the conditioning context and injected with saline or fluoxetine $\left(10 \mathrm{mg} \mathrm{kg}^{-1}\right.$, i.p.) on the following day. Rats were either conditioned an hour after the injection and killed $2 \mathrm{~h}$ later (saline- and fluoxetine-conditioned groups) or were directly killed $3 \mathrm{~h}$ after the injection (saline and fluoxetine naive groups). The brain tissue was then processed for immunohistochemistry. (b) Low magnification images of brain sections from the four treatment groups to show Arc protein expression in the amygdala; bar $=500 \mu \mathrm{m}$. (c-e) representative images of Arc protein expression in the LA, BA and CeA, respectively; bar $=40 \mu \mathrm{m}$. ( $\mathrm{f}-\mathrm{h})$ Quantification of Arc-expressing cells across the four treatment groups in the LA, BA and CeA, respectively. Saline naive (sal naive): $N=4$, fluoxetine naive (flx naive): $N=4$, saline conditioned (sal cond): $N=6$, fluoxetine conditioned (flx cond.): $N=6$. Error bars indicate mean \pm s.e.m. and ${ }^{*} P<0.05$.

treated rats than saline-treated controls (Figure 1c; repeated measures ANOVA: $F_{(1,25)}=4.33, P<0.05$ and Figure $1 \mathrm{~d}$; $\left.t_{(25)}=2.1, P<0.05\right)$. The baseline levels of freezing measured during the 30 -s period immediately before tone onset did not differ between the groups $\left(t_{(25)}=0.08, P=0.94\right)$, indicating that the enhancement in fear elicited by fluoxetine was specific to the learned association. These results are consistent with a previous study showing that a single injection of the SSRI citalopram before fear conditioning also enhances the acquisition of auditory fear memory. ${ }^{16}$
Acute systemic fluoxetine administration enhances Arc protein expression in the CeA but not LA or BA. We next investigated which specific components of the neural circuitry underlying fear learning might serve as substrates for the fear-enhancing effect of fluoxetine. An effective strategy for such an analysis comes from numerous studies in which the IEG Arc has been used to identify cells that are activated and undergo plasticity in response to behaviorally relevant stimuli. ${ }^{34-38}$ Using this approach, a recent study has shown that auditory fear conditioning induces Arc expression in the 
a

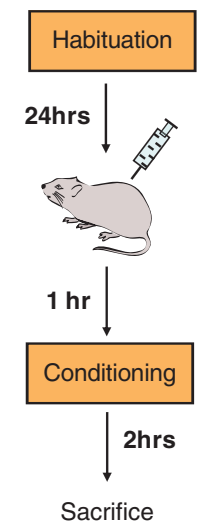

b

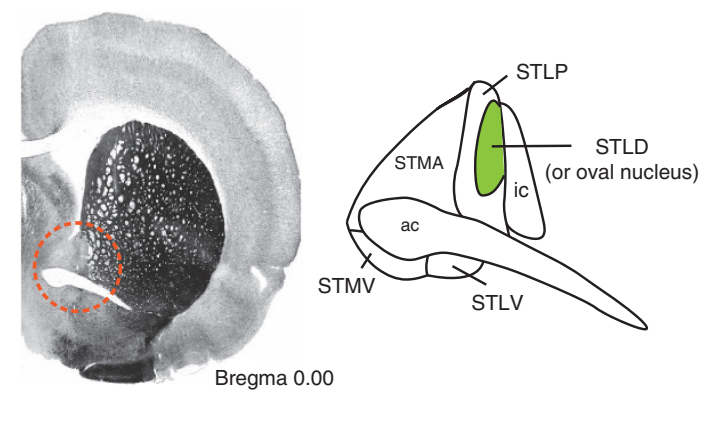

C
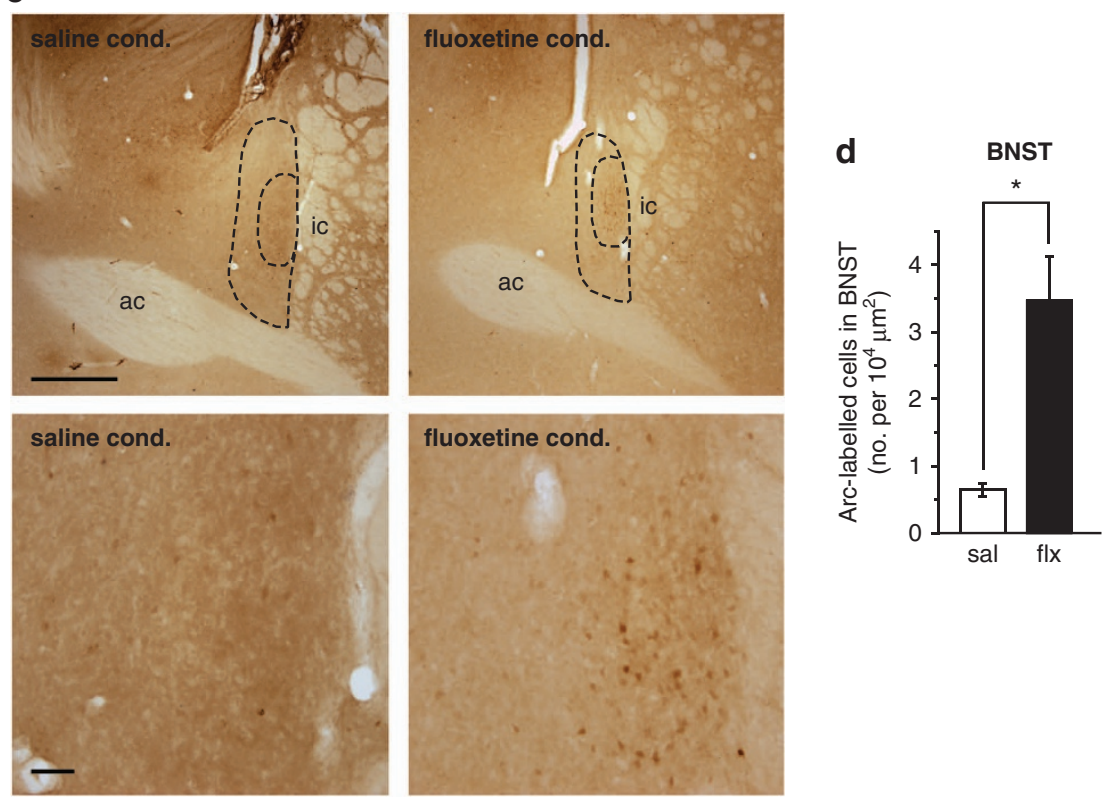

Figure 3 Acute systemic fluoxetine treatment induces Arc (activity-regulated cytoskeleton-associated protein) expression in the bed nucleus of the stria terminalis (BNST). (a) Schematic representation of the experimental protocol. Rats were habituated to the conditioning context and injected with saline or fluoxetine $\left(10 \mathrm{mg} \mathrm{kg}{ }^{-1}\right.$, i.p.) on the following day. Rats were conditioned an hour after the injection and killed $2 \mathrm{~h}$ later. The brain tissue was then processed for immunohistochemistry. (b) Left, sample coronal brain section containing the BNST, marked in a red dotted circle (Paxinos and Watson ${ }^{31}$ ); right, schematic of the principal BNST sub-regions (STLD, BNST lateral-dorsal or oval nucleus; STLP, BNST lateral-posterior; STLV, BNST lateral-ventral; STMV, BNST medial-ventral; STMA, BNST medial-anterior; ac, anterior commissure, ic, internal capsule). (c) Representative images of Arc protein expression in the BNST. Top panel: low magnification images of the BNST from the saline (left)- and fluoxetine (right)injected rats; bar $=500 \mu \mathrm{m}$; bottom panel: higher magnification images of the BNST from the top panel; bar $=50 \mu \mathrm{m}$. (d) Quantification of Arc-expressing cells in the BNST. Saline conditioned (sal): $N=3$, fluoxetine conditioned (f|x): $N=3$. Error bars indicate mean \pm s.e.m. and ${ }^{*} P<0.05$.

LA and BA and that this upregulation of Arc is essential for the expression of fear memory. ${ }^{27}$ We therefore hypothesized that acute fluoxetine administration may enhance fear memory by promoting plasticity in the LA and BA, thereby leading to an increase in Arc protein expression in these regions. To test this hypothesis, we administered a single injection of fluoxetine $\left(10 \mathrm{mg} \mathrm{kg}^{-1}\right.$, i.p.) to rats $1 \mathrm{~h}$ before fear conditioning. Two hours after conditioning, the rats were killed and behaviorally induced Arc protein expression was quantified in the LA, BA and CeA (Figure 2a). To dissociate the effects of fluoxetine on baseline amygdala activity from those specifically triggered by fear conditioning, we injected a separate group of naive rats with the same dose of fluoxetine, returned them to their home cage and killed them 3h later (Figure 2a). Statistical analysis using a two-way ANOVA showed a significant effect of fear conditioning in the LA and BA (LA: $F_{(1,16)}=11.81, P<0.01$; BA: $F_{(1,16)}=15.11$, $P<0.01$ ), indicating that there was more Arc protein expression in both the regions of fear conditioned animals than naive controls (Figures $2 b-d$, $f$ and $g$ ). This is in agreement with earlier work showing that Arc expression is induced by auditory fear conditioning in these sub-regions of the amygdala. ${ }^{27}$ Strikingly, Arc expression in the LA and BA was not affected by pre-treatment with fluoxetine (LA: $F_{(1,16)}=0.10, \quad P=0.76 ; \quad$ BA: $\quad F_{(1,16)}=0.002, \quad P=0.96$; Figures $2 b-d, f$ and $g$ ), and there was no interaction between fear conditioning and fluoxetine treatment (LA: $F_{(1,16)}=0.95$, $P=0.34$; BA: $\left.F_{(1,16)}=0.37, P=0.55\right)$. By contrast, a two-way 
a
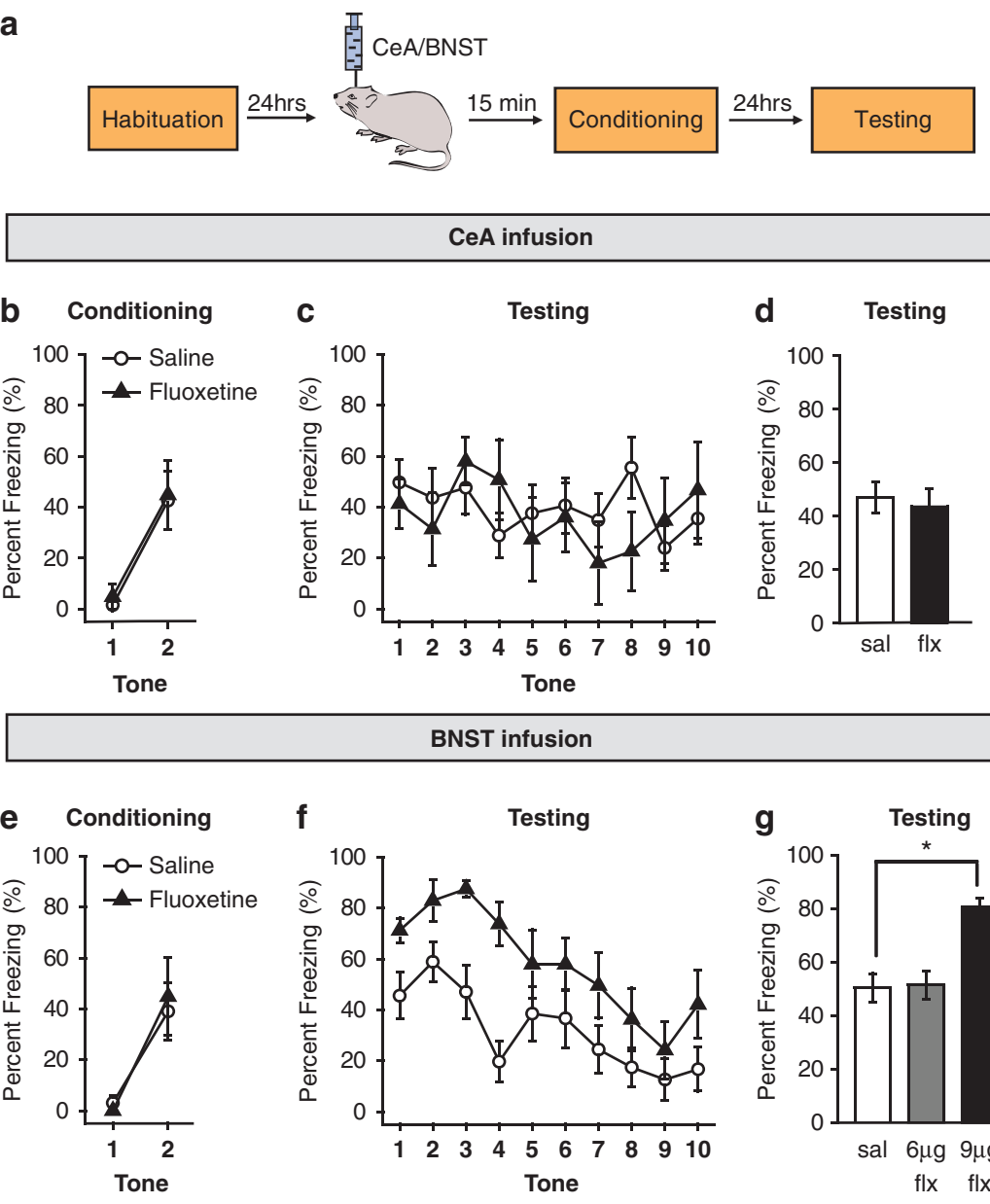

\section{BNST infusion}
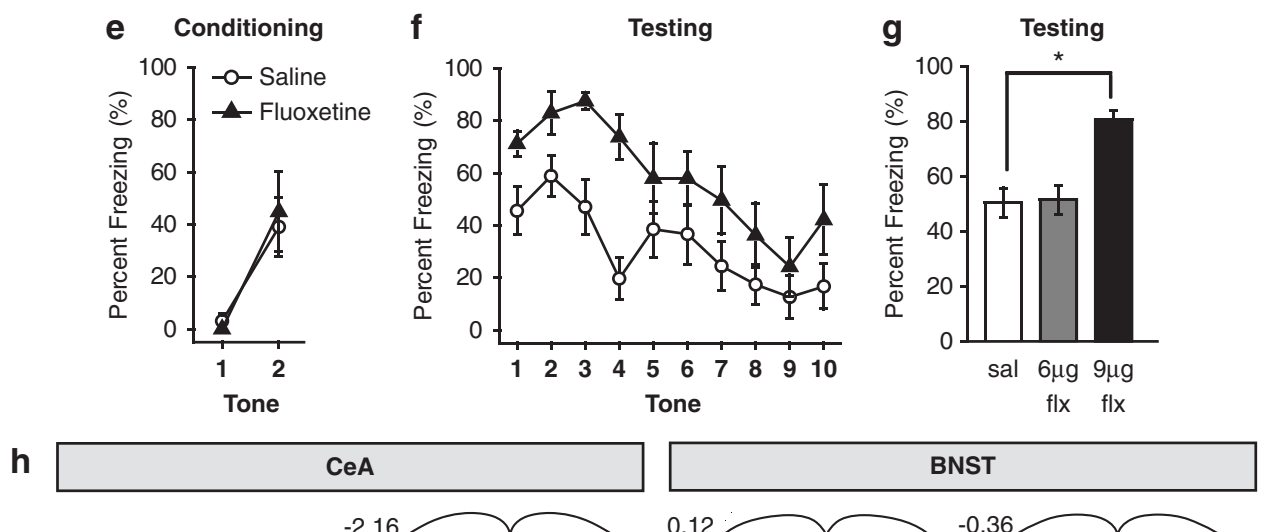

O Saline (CeA, BNST)

$\triangle$ Fluoxetine $6 \mu \mathrm{g}$ (BNST)

$\Delta$ Fluoxetine $9 \mu \mathrm{g}(\mathrm{CeA}, \mathrm{BNST})$
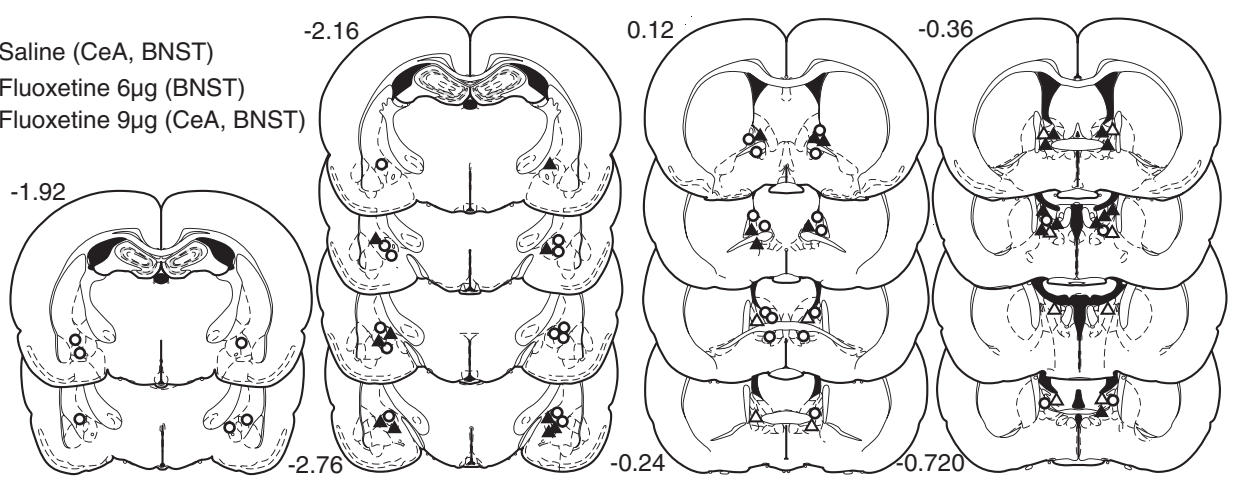

Figure 4 Direct local infusion of fluoxetine into the bed nucleus of the stria terminalis (BNST), but not to the central nucleus of the amygdala (CeA), before fear conditioning enhances conditioned fear memory. (a) Schematic representation of the experimental protocol. Rats were habituated to the conditioning context and infused with saline or fluoxetine ( $9 \mu \mathrm{g}$ per side unless mentioned otherwise) in the CeA or BNST on the following day. Fifteen minutes after the drug infusion, they were conditioned with two conditioned stimulus-unconditioned stimulus (CS-US) pairings. Rats were then tested for conditioned fear in response to $10 \mathrm{CS}$ presentations on the next day. (b,e) Percentage of time spent freezing in response to tone presentations on the conditioning day for the intra-CeA and intra-BNST infusion animals, respectively. (c, $\mathbf{f})$ Percentage of time spent freezing in response to tone presentations on the testing day for the intra-CeA and intra-BNST infusion animals, respectively. (d, $\mathbf{g})$ Percentage of time spent freezing in response to the first three tones on the testing day for the intra-CeA and intra-BNST infusion animals, respectively. (h) Cannula tip placements from rats infused used with saline, fluoxetine$6 \mu \mathrm{g}$ per side and fluoxetine-9 $\mu \mathrm{g}$ per side in the CeA (first and second column; Bregma -1.92 to $-2.76 \mathrm{~mm}$ ) and BNST (third and fourth column; Bregma +0.12 to $-0.72 \mathrm{~mm}$ ) before fear conditioning. CeA saline infusion (sal): $N=11$, CeA fluoxetine infusion $-9 \mu \mathrm{g}$ per side (flx): $N=5$, BNST saline infusion (sal): $N=9$, BNST fluoxetine infusion $-6 \mu \mathrm{g}$ per side $(6 \mu \mathrm{g} f \mathrm{~lx}): N=6$, BNST fluoxetine infusion $-9 \mu \mathrm{g}$ per side $(9 \mu \mathrm{g} f \mathrm{~lx}): N=8$. Error bars indicate mean \pm s.e.m. and ${ }^{*} P<0.05$.

ANOVA revealed a significant main effect of fluoxetine treatment on Arc protein expression in the $\mathrm{CeA}$ $\left(F_{(1,16)}=9.26, \quad P<0.01\right.$; Figures $2 \mathrm{~b}, \mathrm{e}$ and $\left.\mathrm{h}\right)$. Pairwise comparisons reveal that while systemic fluoxetine treatment had no significant effect in naive animals, rats treated with fluoxetine before fear conditioning showed significantly 

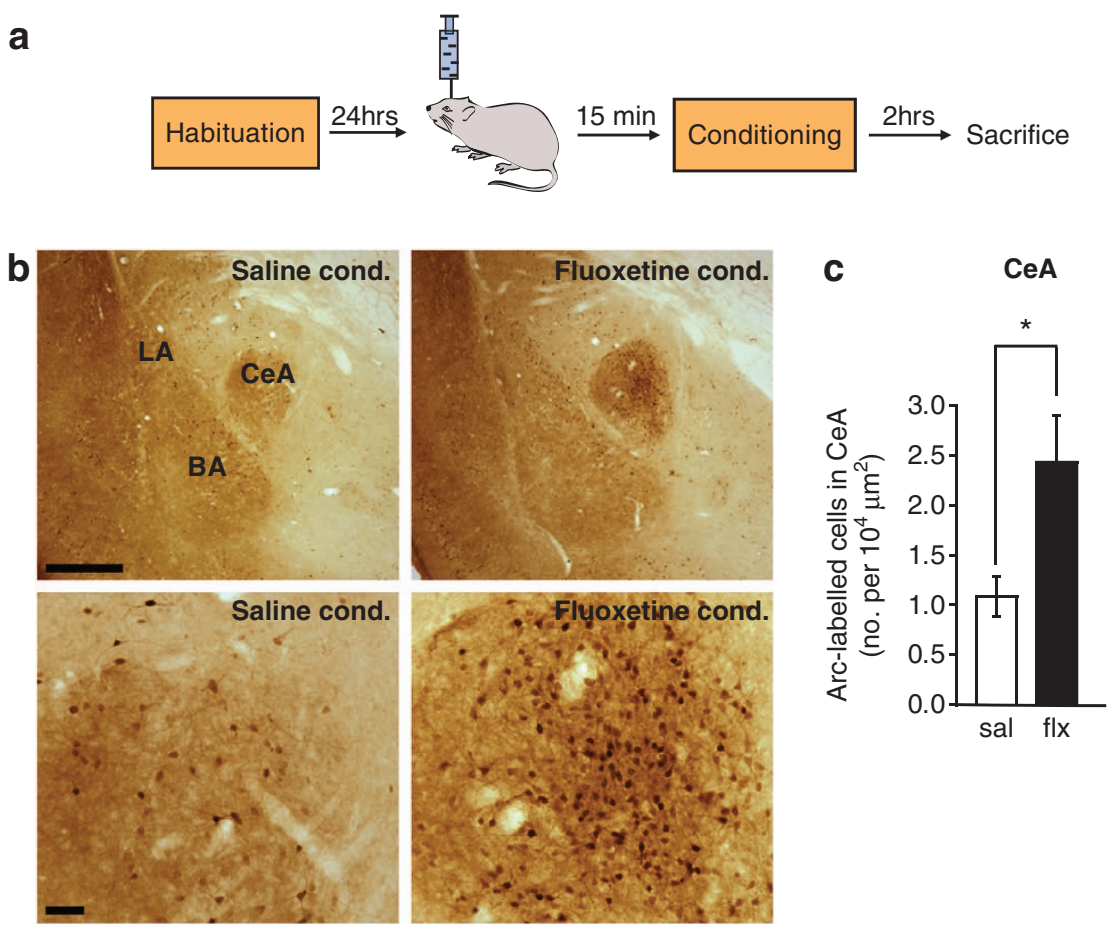

Figure 5 Direct local infusion of fluoxetine into the bed nucleus of the stria terminalis (BNST) before fear conditioning induces Arc (activity-regulated cytoskeletonassociated protein) expression in the central nucleus of the amygdala (CeA). (a) Schematic representation of the experimental protocol. Rats were habituated to the conditioning context and infused with saline or fluoxetine $(9 \mu \mathrm{g}$ per side) in the CeA or BNST on the following day. Fifteen minutes after the drug infusion, they were conditioned with two conditioned stimulus-unconditioned stimulus (CS-US) pairings. Two hours after conditioning, they were killed, and the brain tissue was processed for immunohistochemistry. (b) Representative images of Arc protein expression in the CeA. Top panel: low magnification images of the amygdala from the saline-infused (left) and fluoxetine-infused (right) rats; bar $=500 \mu \mathrm{m}$; bottom panel: high magnification images of the CeA from the top panel; bar $=50 \mu \mathrm{m}$. (c) Quantification of Arc-expressing cells in the CeA. Saline infusion (sal): $N=10$, fluoxetine infusion (flx) $-9 \mu \mathrm{g}$ per side: $N=9$. Error bars indicate mean \pm s.e.m. and ${ }^{*} P<0.05$. BA, basal nucleus of the amygdala; LA, lateral nucleus of the amygdala.

enhanced Arc protein expression in the CeA compared with saline-treated rats (Tukey's HSD (honestly significant difference), $P<0.05$; Figure $2 \mathrm{~h}$ ). Fear conditioning also had a significant effect on Arc expression in the CeA $\left(F_{(1,16)}=5.89\right.$, $P<0.05$; Figure $2 \mathrm{~h}$ ). However, the interaction between fear conditioning and fluoxetine treatment was not significant $\left(F_{(1,16)}=2.98, P=0.10\right)$. These results suggest that the facilitation of fear memory by acute systemic treatment with fluoxetine is accompanied by activation of the $\mathrm{CeA}$ and raise the possibility that this activation may underlie the behavioral effect.

Acute systemic fluoxetine administration induces Arc protein expression in the BNST. The CeA and the BNST serve as the principal output structures of the extended amygdaloid complex that project to the brainstem and hypothalamus and mediate the expression of fear responses. ${ }^{23,24,39}$ In addition to being highly interconnected, the BNST and CeA have been shown to have important roles in modulating fear and anxiety. ${ }^{40-42}$ Given this anatomical and functional relationship and our above finding that acute systemic fluoxetine enhanced Arc expression in the CeA, we examined the pattern of Arc protein in the BNST $2 \mathrm{~h}$ after rats pre-treated with acute systemic fluoxetine were fear conditioned (Figure 3a). Consistent with our hypothesis, we found that a single injection of fluoxetine also triggered Arc expression in the dorsolateral region of the BNST (Figures $3 \mathrm{c}$ and $\left.\mathrm{d} ; t_{(2.1)}=4.28, P<0.5\right)$.

Finally, we examined whether Arc expression is enhanced by fluoxetine in other brain regions involved in fear learning. Previous work has shown that an acute SSRI injection decreases contextual fear conditioning, ${ }^{43,44}$ a form of fear learning that is hippocampal-dependent. ${ }^{45,46}$ Strikingly, in contrast to the CeA and the BNST, we found that fluoxetine treatment had the opposite effect on the DG of the hippocampus, a brain region that has been previously implicated in antidepressant action. ${ }^{47}$ Acute fluoxetine treatment significantly decreased Arc protein expression in the DG in both the naive and fear-conditioned animals (Supplementary Figure S1; $F_{(1,16)}=19.41, P<0.001$ ), while fear conditioning itself had no effect on Arc expression (Supplementary Figure S1; $F_{(1,16)}=0.07, P=0.79$ ).

\section{Direct local infusion of fluoxetine into the CeA does not} enhance conditioned fear memory. Our results demonstrate that a systemic injection of fluoxetine enhances Arc protein expression in two output nuclei of the extended amygdala: the BNST and the CeA. To determine whether fluoxetine is acting directly on neurons in these two structures to enhance fear conditioning, we tested the effects of local infusions of fluoxetine targeted at either the $\mathrm{CeA}$ or the BNST. 
We first tested the possibility that activation of CeA by fluoxetine is sufficient to modify fear behavior. If this is true, then local infusion of fluoxetine into the $\mathrm{CeA}$ before conditioning should also enhance auditory fear memory, as was observed with systemic treatment. We bilaterally infused fluoxetine $(9 \mu \mathrm{g}$ per side) directly into the CeA $(-2.5 \mathrm{~mm} \mathrm{AP}$, $+/-4.3 \mathrm{~mm} \mathrm{ML},-8.0 \mathrm{~mm} \mathrm{DV}$ ) $15 \mathrm{~min}$ before the conditioning session and measured CS-elicited freezing behavior $24 \mathrm{~h}$ later (Figure 4a). Intra-CeA fluoxetine infusions did not affect freezing during the conditioning session (Figure $4 \mathrm{~b}$; repeated measures ANOVA: $\left.F_{(1,14)}=0.59, P=0.46\right)$. Surprisingly, we found that intra-CeA fluoxetine infusions before conditioning also did not affect freezing measured during the testing session (Figure 4c; repeated measures ANOVA: $F_{(1,14)}=0.10, \quad P=0.76$ and Figure $4 \mathrm{~d} ; \quad t_{(14)}=0.2528$, $P=0.80)$. This suggests that targeted infusion of fluoxetine into the $\mathrm{CeA}$ alone is not sufficient to produce the same behavioral effects as acute systemic treatment.

Direct local infusion of fluoxetine into the bed nucleus of the stria terminalis (BNST), is sufficient to enhance conditioned fear memory. Given that Arc expression was also enhanced in the BNST following systemic fluoxetine administration coupled with fear conditioning, we next examined whether local infusions of fluoxetine into the BNST would enhance fear conditioning. We bilaterally infused rats with fluoxetine ( 6 or $9 \mu \mathrm{g}$ per side) in the BNST $15 \mathrm{~min}$ before fear conditioning and measured the freezing response to the CS $24 \mathrm{~h}$ later (Figure 4a). These infusions targeted the dorsolateral and dorsomedial nuclei of the BNST $(-0.6 \mathrm{~mm}$ $\mathrm{AP},+/-1.5 \mathrm{ML},-6.5 \mathrm{~mm} \mathrm{DV})$, and infusion cannulae tracks in all the experimental animals were limited to 0.12 to $-0.72 \mathrm{~mm}$ Bregma (Figure 4h). These coordinates were chosen based on earlier studies ${ }^{48}$ that characterized the electrophysiological properties of BNST neurons in the area dorsal to the anterior commissure, between 0.0 and $-0.6 \mathrm{~mm}$ Bregma. Intra-BNST fluoxetine infusions did not affect freezing during the conditioning session (Figure 4e; repeated measures ANOVA: $\left.F_{(1,15)}=0.01, P=0.91\right)$. Interestingly, we found that the intra-BNST fluoxetine enhanced fear memory recall during the testing session $24 \mathrm{~h}$ later. Moreover, this fear-enhancing effect was dose-dependent (Figure 4g; one-way ANOVA: $F_{(2,20)}=7.80, \quad P<0.01$ ). Although the lower dose of $6 \mu \mathrm{g}$ per side did not affect memory recall (Figure 4g; Tukey's HSD: $P=0.99$ ), a higher dose of $9 \mu \mathrm{g}$ per side was sufficient to elicit a significant enhancement in fear memory during the testing session (Figure 4f; repeated measures ANOVA: $F_{(1,15)}=8.52$, $P<0.05$ and Figure 4g; Tukey's HSD: $P<0.01)$. Thus, a single infusion of fluoxetine directly into the BNST produced the same behavioral effect on fear memory recall as a single systemic injection of fluoxetine.

\footnotetext{
Direct local infusion of fluoxetine into the BNST before fear conditioning enhances Arc protein expression in the CeA. Together, our results suggest that the BNST may be a primary site of action for fluoxetine and may mediate the behavioral enhancement of fear memory seen after acute systemic fluoxetine treatment. However, as shown earlier, systemic fluoxetine treatment also led to enhanced Arc
}

expression in the CeA. Does direct infusion of fluoxetine into the BNST cause the same effect in the CeA? To address this question, behaviorally induced Arc protein expression was evaluated in the CeA of rats infused with fluoxetine $(9 \mu \mathrm{g}$ per side) in the BNST $15 \mathrm{~min}$ before fear conditioning and killed $2 \mathrm{~h}$ later (Figure $5 \mathrm{a}$ ). We found that intra-BNST fluoxetine infusion did enhance Arc protein expression in the $\mathrm{CeA}$ (Figures $5 \mathrm{~b}$ and $\mathrm{c} ; t_{(10.7)}=2.6, P<0.5$ ). Thus, similar to systemic acute administration of fluoxetine, the facilitation of fear memory recall caused by intra-BNST fluoxetine infusions is also accompanied by the induction of Arc protein expression in the CeA.

\section{Discussion}

Consistent with earlier reports, ${ }^{16}$ we found that a single injection of fluoxetine immediately before conditioning enhances the recall of fear memory a day later. Surprisingly, fluoxetine pretreatment was accompanied by increased Arc protein expression in the CeA and BNST but not in the LA or BA. This is consistent with recent reports identifying a critical role for the $\mathrm{CeA}$ in the acquisition of auditory fear memory. ${ }^{19,49}$ Although enhanced Arc expression in the CeA suggested a potential role for this structure in enhancing fear memory after acute systemic treatment with SSRIs, we found that local infusion of fluoxetine directly into the CeA did not affect fear memory. Instead, local infusion of fluoxetine into the BNST, a closely related component of the extended amygdala, was sufficient to enhance both fear memory and Arc protein expression in the $\mathrm{CeA}$. Together these results suggest that systemically administered fluoxetine may act within the BNST to drive both Arc expression in the $\mathrm{CeA}$ and enhance fear learning.

The acute effects of SSRI treatment on fear and anxiety. The acute effects of SSRIs have been demonstrated in numerous models of anxiety-like behavior. ${ }^{11-15}$ The amygdala is known to be an important component of anxiety circuits in the brain ${ }^{50,51}$ and aberrant amygdala activity is associated with affective symptoms of numerous psychiatric disorders. ${ }^{52-55}$ Furthermore, there are reports that acute administration of SSRIs increase amygdala activity ${ }^{56,57}$ and fear-potentiated startle responses in healthy humans. ${ }^{58}$ Although this work implicates the amygdala in the acute anxiogenic effects of SSRIs, the key unresolved issue was to identify specific components of the amygdala that mediate these effects.

Identifying amygdalar circuits involved in the acute effects of SSRIs. To probe the neural substrates underlying the acute effects of fluoxetine, we analyzed the impact of fluoxetine on the expression of Arc, an IEG that is induced by behaviorally relevant stimuli and has a critical role in consequent synaptic plasticity. ${ }^{59,60}$ Arc mRNA undergoes rapid transport to dendrites and is enriched at local sites of synaptic activity, a process requiring NMDA ( $N$-methyl-Daspartate)-receptor activation. ${ }^{61}$ Fear conditioning, which also requires activation of NMDA receptors, ${ }^{62,63}$ is known to induce the expression of Arc protein in both the LA and BA. Furthermore, this upregulation of Arc is required for the subsequent expression of fear memory. ${ }^{27}$ Although previous studies report that acute SSRI treatment modulates IEG 
expression in naive as well as in stressed animals in several brain areas, including the basolateral amygdala (BLA), medial amygdala, CeA and BNST, ${ }^{15,64-66}$ nothing is known about how SSRIs affect the induction of Arc expression in sub-regions of the amygdala following cued fear conditioning. We hypothesized that acute SSRI treatment may potentiate fear memory by affecting activity of the LA and BA. Surprisingly, we found that fluoxetine pre-treatment had no effect on Arc expression in the LA or BA, despite fear conditioning itself enhancing Arc expression in these areas in the absence of fluoxetine. However, Arc expression in the $\mathrm{CeA}$ was significantly enhanced with fluoxetine treatment, suggesting a role for $\mathrm{CeA}$ activation in fluoxetine-induced potentiation of fear memory.

It is interesting to note that in our study the effect of acute fluoxetine is evident only in the $\mathrm{CeA}$ of fear conditioned, but not naive, animals. It is possible that fluoxetine, which increases extracellular levels of serotonin by blocking the serotonin transporter, does not change Arc levels under baseline conditions, because levels of serotonin are low. During fear conditioning, serotonin levels increase ${ }^{67-69}$ and are further elevated by blockade of the serotonin transporter, both of which appear to be required for Arc expression in the CeA to increase.

Role of the extended amygdala. The CeA is the primary output nucleus of the amygdaloid complex that mediates the expression of conditioned fear responses via its projections to downstream brain areas. ${ }^{23}$ Although much attention has focused on the role of the BLA in the acquisition of auditory fear conditioning, several recent studies show that the $\mathrm{CeA}$ may function in parallel with the BLA to make distinct contributions to fear and anxiety-like behavior. Indeed, inactivation of the $\mathrm{CeA}$ impairs fear learning, ${ }^{70,71}$ and rats with BLA lesions can learn conditioned fear responses in an associative, CeA-dependent manner. ${ }^{72,73}$ Importantly, activity-dependent plasticity within the $\mathrm{CeA}$ is essential for the acquisition of fear conditioning. ${ }^{25,65,66}$ Moreover, diverse agents ranging from alcohol to neuropeptides like oxytocin are known to produce anxiolytic effects by modulating inhibitory microcircuits in the $\mathrm{CeA} .^{74,75}$

Although our data suggest that elevation of Arc expression in CeA may be a neural correlate of the facilitation of fear memory by systemic fluoxetine, direct infusion of fluoxetine into the CeA failed to enhance fear memory. This indicates that fluoxetine does not mediate its behavioral effects on fear conditioning by acting directly on the $\mathrm{CeA}$ and instead raises the possibility that fluoxetine may act on other brain areas that, in turn, project to the CeA to modulate fear memory. Indeed, systemic fluoxetine treatment similarly increased Arc protein expression in the BNST. We found that direct infusion of fluoxetine into the BNST before conditioning was sufficient to enhance both fear memory, as well as Arc expression in the $\mathrm{CeA}$. In other words, the direct action of fluoxetine on the BNST has the same functional consequences as systemic treatment.

To evaluate whether the upregulation of Arc expression is specific to the CeA and BNST, we also analyzed Arc expression in the DG of the hippocampus. We found that fluoxetine treatment decreased Arc expression in the $D G$ regardless of whether or not animals were fear conditioned, providing further support for a specific role of the extended amygdala in the acute effects of fluoxetine. This result is consistent with earlier reports of a decrease in hippocampusdependent contextual fear memory following acute SSRI treatment. ${ }^{43,44}$ These results are also interesting in light of studies that implicate the hippocampus in antidepressant effects $^{47}$ and reports of contrasting effects of stress on the hippocampus and amygdala ${ }^{76}$ and warrant further investigation in future studies.

The involvement of both the BNST and CeA is intriguing because of substantial evidence that the two regions mediate distinct fear responses, despite their extensive similarities. The $\mathrm{CeA}$ is an integral part of fear circuits that mediate stimulus-specific conditioned fear responses to discrete sensory cues and is essential for the acquisition and expression of auditory fear conditioning. ${ }^{17,26}$ On the other hand, the BNST is not necessary for acquisition or expression of fear to a discrete conditioned cue. ${ }^{23,77-79}$ Instead, the BNST mediates non-specific, 'anxiety-like' sustained fear states in response to more diffuse environmental contingencies, such as light-induced startle and corticotropin-releasing factor-induced anxiety. ${ }^{26}$ However, many recent studies suggest that the two fear systems do interact and are not completely independent. For instance, although the BNST is not required for conditioned fear responses to brief sensory cues, it is required for conditioned responses to long duration cues paired with a shock. ${ }^{80,81}$ The BNST is also required for contextual fear conditioning. ${ }^{77,82,83}$ Further, animals with BNST lesions display less fear generalization. ${ }^{82}$ Together, these studies suggest that although the BNST is not involved directly in the formation of brief stimulus-specific memory, other aspects of conditioned fear, such as the effect of context and stimulus specificity, may be modulated by the BNST.

Our results suggest that although the BNST is not normally required for the acquisition and expression of conditioned fear memory, acute systemic fluoxetine treatment recruits the BNST into the fear circuitry, leading to an increase in fear memory, possibly mediated via the CeA. Although our experiments suggest that pre-treatment with fluoxetine engages the BNST during fear learning, our data does not address whether the BNST is also active during memory recall. Future studies aimed at measuring IEG expression in the BNST during fear expression may help in addressing this possibility. Further, studies involving transient inactivation of the BNST during the conditioning or testing sessions in different groups of rats pre-treated with fluoxetine will help verify a role for the BNST in the acquisition and expression of conditioned fear.

The results presented here raise questions regarding how SSRIs modulate BNST function. The increased availability of serotonin (5-hydroxytryptamine (5-HT)) due to SSRIs may act on numerous candidate 5 -HT receptors in the BNST. ${ }^{41,84}$ Interestingly, activation of the $5-\mathrm{HT}_{2 \mathrm{~A} / 2 \mathrm{C} / 7}$ receptor sub-types in vitro mediates an excitatory response to $5-\mathrm{HT}$ that may be anxiogenic. ${ }^{41}$ Consistent with this, pre-treatment of rats with a $5-\mathrm{HT}_{2 \mathrm{C}}$ antagonist blocked the acute fear-enhancing effect of the SSRI citalopram. ${ }^{28}$ Conversely, systemic activation of 5$\mathrm{HT}_{2 \mathrm{C}}$ receptors in rats is anxiogenic ${ }^{85}$ and increases the expression of $\mathrm{c}$-fos in the anterolateral BNST. ${ }^{86}$ The activation 
of BNST by acute SSRI treatment may therefore be mediated by the activation of specific 5-HT receptors on BNST neurons, a possibility that awaits further analysis.

In conclusion, our findings demonstrate that the direct action of fluoxetine in BNST successfully replicates the consequences of acute systemic fluoxetine treatment in terms of a molecular marker of activity and plasticity (induction of Arc expression), its enhanced expression in a specific circuit within the amygdala (CeA) and its behavioral impact (enhanced fear memory recall). The BNST appears to have a novel modulatory role in generating stimulus-specific conditioned fear responses, which are also known to involve the $\mathrm{CeA} .{ }^{87}$ In this regard, our results reflect the importance of expanding our focus from the BLA to output structures of the amygdaloid complex, such as the $\mathrm{CeA}$ and BNST. Future studies will be needed to address what the precise role of the $\mathrm{CeA}$ is in the acute effects of SSRIs on fear memory and whether this is any different from its normal role during fear acquisition and expression in the absence of SSRIs. This will require an understanding of what specific cellular populations and connections between the CeA and BNST mediate such modulatory influences. Such an approach is likely to provide a more comprehensive experimental framework for studying these short-term undesirable effects as well as the therapeutic effects of long-term SSRI treatment.

\section{Conflict of interest}

The authors declare no conflict of interest.

Acknowledgements. This research was supported by the National Centre for Biological Sciences (Grant no. 1143 to SC), the SfN-Neuroscience Scholars Program to NSB and a grant to Barnard College from the Undergraduate Science Education Program of the Howard Hughes Medical Institute. We thank Prof. Andreas Luthi for his helpful advice.

1. Kent JM, Coplan JD, Gorman JM. Clinical utility of the selective serotonin reuptake inhibitors in the spectrum of anxiety. Biol Psychiatry 1998; 44: 812-824.

2. Sheehan DV, Raj BA, Trehan RR, Knapp EL. Serotonin in panic disorder and social phobia. Int Clin Psychopharmacol 1993; 8: 63-77.

3. van der Kolk BA, Dreyfuss D, Michaels M, Shera D, Berkowitz R, Fisler R et al. Fluoxetine in posttraumatic stress disorder. J Clin Psychiatry 1994; 55: 517-522.

4. Gorman JM. Treating generalized anxiety disorder. J Clin Psychiatry 2003; 64: 24-29.

5. Gorman JM, Liebowitz MR, Fyer AJ, Goetz D, Campeas RB, Fyer MR et al. An open trial of fluoxetine in the treatment of panic attacks. J Clin Psychopharmacol 1987; 7: 329-332.

6. Teicher MH, Glod C, Cole JO. Emergence of intense suicidal preoccupation during fluoxetine treatment. Am J Psychiatry 1990; 147: 207-210.

7. Mir S, Taylor D. The adverse effects of antidepressants. Curr Opin Psychitary 1997; 10: 88-94.

8. Spigset $\mathrm{O}$. Adverse reactions of selective serotonin reuptake inhibitors-Reports from a spontaneous reporting system. Drug Saf 1999; 20: 277-287.

9. Fergusson D, Doucette S, Cranley K, Glass KC, Shapiro S, Healy D et al. Association between suicide attempts and selective serotonin reuptake inhibitors: systematic review of randomised controlled trials. Br Med J 2005; 330: 396-399.

10. Masand PS, Gupta S. Selective serotonin-reuptake inhibitors: an update. Harv Rev Psychiatry 1999; 7: 69-84.

11. Ravinder S, Pillai AG, Chattarji S. Cellular correlates of enhanced anxiety caused by acute treatment with the selective serotonin reuptake inhibitor fluoxetine in rats. Front Behav Neurosci 2011; 5: 88.

12. Griebel G, Moreau JL, Jenck F, Misslin R, Martin JR. Acute and chronic treatment with 5-HT reuptake inhibitors differentially modulate emotional responses in anxiety models in rodents. Psychopharmacology (Berl) 1994; 113: 463-470.

13. Sanchez C, Meier E. Behavioral profiles of SSRIs in animal models of depression, anxiety and aggression-Are they all alike? Psychopharmacology (Berl) 1997; 129: 197-205.
14. Dekeyne A, Denorme B, Monneyron S, Millan MJ. Citalopram reduces social interaction in rats by activation of serotonin $(5-\mathrm{HT})(2 \mathrm{C})$ receptors. Neuropharmacology 2000; 39: 1114-1117.

15. Salchner $P$, Singewald N. Neuroanatomical substrates involved in the anxiogenic-like effect of acute fluoxetine treatment. Neuropharmacology 2002; 43: 1238-1248.

16. Burghardt NS, Sullivan GM, McEwen BS, Gorman JM, LeDoux JE. The selective serotonin reuptake inhibitor citalopram increases fear after acute treatment but reduces fear with chronic treatment: A comparison with tianeptine. Biol Psychiatry 2004; 55: 1171-1178.

17. LeDoux JE. Emotion circuits in the brain. Annu Rev Neurosci 2000; 23: 155-184.

18. Sah P, Faber ES, Lopez De Armentia M, Power J. The amygdaloid complex: anatomy and physiology. Physiol Rev 2003; 83: 803-834.

19. Ehrlich I, Humeau Y, Grenier F, Ciocchi S, Herry C, Luthi A. Amygdala inhibitory circuits and the control of fear memory. Neuron 2009; 62: 757-771.

20. Maren S, Quirk GJ. Neuronal signalling of fear memory. Nat Rev Neurosci 2004; 5: 844-852.

21. McDonald AJ. Cortical pathways to the mammalian amygdala. Prog Neurobiol 1998; 55 : 257-332.

22. Turner $\mathrm{BH}$, Herkenham M. Thalamoamygdaloid projections in the rat: a test of the amygdala's role in sensory processing. J Comp Neurol 1991; 313: 295-325.

23. LeDoux JE, Iwata J, Cicchetti P, Reis DJ. Different projections of the central amygdaloid nucleus mediate autonomic and behavioral correlates of conditioned fear. J Neurosci 1988; 8: 2517-2529.

24. Petrovich GD, Swanson LW. Projections from the lateral part of the central amygdalar nucleus to the postulated fear conditioning circuit. Brain Res 1997; 763: 247-254.

25. Duvarci S, Popa D, Pare D. Central amygdala activity during fear conditioning. J Neurosci 2011; 31: 289-294.

26. Walker DL, Toufexis DJ, Davis M. Role of the bed nucleus of the stria terminalis versus the amygdala in fear, stress, and anxiety. Eur J Pharmacol 2003; 463: 199-216.

27. Ploski JE, Pierre VJ, Smucny J, Park K, Monsey MS, Overeem KA et al. The activityregulated cytoskeletal-associated protein (Arc/Arg3.1) is required for memory consolidation of pavlovian fear conditioning in the lateral amygdala. J Neurosci 2008; 28: 12383-12395.

28. Burghardt NS, Bush DEA, McEwen BS, LeDoux JE. Acute selective serotonin reuptake inhibitors increase conditioned fear expression: blockade with a 5-HT2C receptor antagonist. Biol Psychiatry 2007; 62: 1111-1118.

29. Bodnoff SR, Suranyi-Cadotte B, Quirion R, Meaney MJ. A comparison of the effects of diazepam versus several typical and atypical anti-depressant drugs in an animal model of anxiety. Psychopharmacology (Berl) 1989; 97: 277-279.

30. Silva RCB, Brandao ML. Acute and chronic effects of gepirone and fluoxetine in rats tested in the elevated plus-maze: an ethological analysis. Pharmacol Biochem Behav 2000; 65: 209-216.

31. Paxinos G, Watson C. The Rat Brain in Stereotaxic Coordinates. Academic Press, Elsevier Inc.: San Diego, USA, 2009.

32. Garrigou D, Broekkamp CL, Lloyd KG. Involvement of the amygdala in the effect of antidepressants on the passive avoidance deficit in bulbectomised rats. Psychopharmacology (Berl) 1981; 74: 66-70.

33. Lee EH, Lin WR, Chen HY, Shiu WH, Liang KC. Fluoxetine and 8-OH-DPAT in the lateral septum enhances and impairs retention of an inhibitory avoidance response in rats. Physiol Behav 1992; 51: 681-688.

34. Mamiya N, Fukushima H, Suzuki A, Matsuyama Z, Homma S, Frankland PW et al. Brain region-specific gene expression activation required for reconsolidation and extinction of contextual fear memory. J Neurosci 2009; 29: 402-413.

35. Pandey SC, Zhang H, Ugale R, Prakash A, Xu T, Misra K. Effector immediate-early gene arc in the amygdala plays a critical role in alcoholism. $J$ Neurosci 2008; 28: 2589-2600.

36. Ramirez-Amaya V, Vazdarjanova A, Mikhael D, Rosi S, Worley PF, Barnes CA. Spatial exploration-induced Arc mRNA and protein expression: evidence for selective, networkspecific reactivation. J Neurosci 2005; 25: 1761-1768.

37. Guzowski JF, Timlin JA, Roysam B, McNaughton BL, Worley PF, Barnes CA. Mapping behaviorally relevant neural circuits with immediate-early gene expression. Curr Opin Neurobiol 2005; 15: 599-606.

38. Montag-Sallaz M, Montag D. Learning-induced arg 3.1/arc mRNA expression in the mouse brain. Learn Mem 2003; 10: 99-107.

39. de Olmos JS, Heimer L. The concepts of the ventral striatopallidal system and extended amygdala. Ann NY Acad Sci 1999; 877: 1-32.

40. Grillon C. Models and mechanisms of anxiety: evidence from startle studies. Psychopharmacology (Berl) 2008; 199: 421-437.

41. Hammack SE, Guo JD, Hazra R, Dabrowska J, Myers KM, Rainnie DG. The response of neurons in the bed nucleus of the stria terminalis to serotonin: implications for anxiety. Prog Neuropsychopharmacol Biol Psychiatry 2009; 33: 1309-1320.

42. Davis M, Walker DL, Miles L, Grillon C. Phasic vs sustained fear in rats and humans: role of the extended amygdala in fear vs anxiety. Neuropsychopharmacology 2010; 35: 105-135.

43. Inoue T, Hashimoto S, Tsuchiya K, Izumi T, Ohmori T, Koyama T. Effect of citalopram, a selective serotonin reuptake inhibitor, on the acquisition of conditioned freezing. Eur $J$ Pharmacol 1996; 311: 1-6.

44. Hashimoto $\mathrm{S}$, Inoue T, Koyama T. Serotonin reuptake inhibitors reduce conditioned fear stress-induced freezing behavior in rats. Psychopharmacology (Berl) 1996; 123: $182-186$. 
45. Phillips RG, LeDoux JE. Differential contribution of amygdala and hippocampus to cued and contextual fear conditioning. Behav Neurosci 1992; 106: 274-285.

46. Rudy JW. Contextual conditioning and auditory cue conditioning dissociate during development. Behav Neurosci 1993; 107: 887-891.

47. Malberg JE, Eisch AJ, Nestler EJ, Duman RS. Chronic antidepressant treatment increases neurogenesis in adult rat hippocampus. J Neurosci 2000; 20: 9104-9110.

48. Rainnie DG. Neurons of the bed nucleus of the stria terminalis (BNST): electrophysiological properties and their response to serotonin. Ann N Y Acad Sci 1999; 877: 695-699.

49. Pare D, Quirk GJ, Ledoux JE. New vistas on amygdala networks in conditioned fear. J Neurophysiol 2004; 92: 1-9.

50. Davis M. The role of the amygdala in fear and anxiety. Annu Rev Neurosci 1992; 15: 353-375.

51. Roozendaal B, McEwen BS, Chattarji S. Stress, memory and the amygdala. Nat Rev Neurosci 2009; 10: 423-433.

52. Anand A, Shekhar A. Brain imaging studies in mood and anxiety disorders. Ann NY Acad Sci 2003; 985: 370-388.

53. Drevets WC. Neuroimaging abnormalities in the amygdala in mood disorders. Ann NY Acad Sci 2003; 985: 420-444.

54. Rauch SL, Shin LM, Wright $\mathrm{Cl}$. Neuroimaging studies of amygdala function in anxiety disorders. Ann NY Acad Sci 2003; 985: 389-410.

55. Hasler G, Northoff G. Discovering imaging endophenotypes for major depression. $\mathrm{Mol}$ Psychiatry 2011; 16: 604-619.

56. Del-Ben CM, Deakin JFW, McKie S, Delvai NA, Williams SR, Elliott $R$ et al. The effect of citalopram pretreatment on neuronal responses to neuropsychological tasks in norma volunteers: an fMRI study. Neuropsychopharmacology 2005; 30: 1724-1734.

57. McKie S, Del-Ben C, Elliott R, Williams S, del Vai N, Anderson I et al. Neuronal effects of acute citalopram detected by pharmacoMRI. Psychopharmacology (Berl) 2005; 180 : 680-686.

58. Grillon C, Levenson J, Pine DS. A single dose of the selective serotonin reuptake inhibito citalopram exacerbates anxiety in humans: a fear-potentiated startle study. Neuropsychopharmacology 2007; 32: 225-231.

59. Shepherd JD, Bear MF. New views of Arc, a master regulator of synaptic plasticity. Nat Neurosci 2011; 14: 279-284.

60. Bramham CR, Worley PF, Moore MJ, Guzowski JF. The immediate early gene arc/arg3.1: regulation, mechanisms, and function. J Neurosci 2008; 28: 11760-11767.

61. Steward O, Worley PF. A cellular mechanism for targeting newly synthesized mRNAs to synaptic sites on dendrites. Proc Natl Acad Sci USA 2001; 98: 7062-7068.

62. Bauer EP, Schafe GE, LeDoux JE. NMDA receptors and L-type voltage-gated calcium channels contribute to long-term potentiation and different components of fear memory formation in the lateral amygdala. J Neurosci 2002; 22: 5239-5249.

63. Rodrigues SM, Schafe GE, LeDoux JE. Intra-amygdala blockade of the NR2B subunit of the NMDA receptor disrupts the acquisition but not the expression of fear conditioning. $J$ Neurosci 2001; 21: 6889-6896.

64. Veening JG, Coolen LM, Spooren WJ, Joosten H, van Oorschot R, Mos J et al. Patterns of c-fos expression induced by fluvoxamine are different after acute vs chronic oral administration. Eur Neuropsychopharmacol 1998; 8: 213-226.

65. Lino-de-Oliveira C, Sales AJ, Del Bel EA, Silveira MC, Guimaraes FS. Effects of acute and chronic fluoxetine treatments on restraint stress-induced Fos expression. Brain Res Bull 2001; 55: 747-754.

66. Izumi T, Inoue T, Kitaichi Y, Nakagawa S, Koyama T. Target brain sites of the anxiolytic effect of citalopram, a selective serotonin reuptake inhibitor. Eur J Pharmacol 2006; 534: 129-132.

67. Zanoveli JM, Carvalho MC, Cunha JM, Brandao ML. Extracellular serotonin level in the basolateral nucleus of the amygdala and dorsal periaqueductal gray under unconditioned and conditioned fear states: an in vivo microdialysis study. Brain Res 2009; 1294: 106-115.

68. Yokoyama M, Suzuki E, Sato T, Maruta S, Watanabe S, Miyaoka H. Amygdalic levels of dopamine and serotonin rise upon exposure to conditioned fear stress without elevation of glutamate. Neurosci Lett 2005; 379: 37-41.
69. Yoshioka M, Matsumoto M, Togashi $\mathrm{H}$, Saito $\mathrm{H}$. Effects of conditioned fear stress on $5-\mathrm{HT}$ release in the rat prefrontal cortex. Pharmacol Biochem Behav 1995; 51: 515-519.

70. Goosens KA, Maren S. Pretraining NMDA receptor blockade in the basolateral complex but not the central nucleus, of the amygdala prevents savings of conditional fear. Behav Neurosci 2003; 117: 738-750.

71. Wilensky AE, Schafe GE, Kristensen MP, LeDoux JE. Rethinking the fear circuit: the central nucleus of the amygdala is required for the acquisition, consolidation, and expression of Pavlovian fear conditioning. J Neurosci 2006; 26: 12387-12396.

72. Rabinak CA, Maren S. Associative structure of fear memory after basolateral amygdala lesions in rats. Behav Neurosci 2008; 122: 1284-1294.

73. Zimmerman JM, Rabinak CA, McLachlan IG, Maren S. The central nucleus of the amygdala is essential for acquiring and expressing conditional fear after overtraining. Learn Mem 2007; 14: 634-644.

74. Huber D, Veinante $P$, Stoop R. Vasopressin and oxytocin excite distinct neuronal populations in the central amygdala. Science 2005; 308: 245-248.

75. Roberto M, Madamba SG, Moore SD, Tallent MK, Siggins GR. Ethanol increases GABAergic transmission at both pre- and postsynaptic sites in rat central amygdala neurons. Proc Natl Acad Sci USA 2003; 100: 2053-2058.

76. Vyas A, Mitra R, Shankaranarayana Rao BS, Chattarji S. Chronic stress induces contrasting patterns of dendritic remodeling in hippocampal and amygdaloid neurons. $J$ Neurosci 2002; 22: 6810-6818.

77. Sullivan GM, Apergis J, Bush DE, Johnson LR, Hou M, Ledoux JE. Lesions in the bed nucleus of the stria terminalis disrupt corticosterone and freezing responses elicited by a contextual but not by a specific cue-conditioned fear stimulus. Neuroscience 2004; 128: 7-14.

78. Hitchcock JM, Davis M. Efferent pathway of the amygdala involved in conditioned fear as measured with the fear-potentiated startle paradigm. Behav Neurosci 1991; 105: 826-842.

79. Treit $\mathrm{D}$, Aujla $\mathrm{H}$, Menard J. Does the bed nucleus of the stria terminalis mediate fear behaviors? Behav Neurosci 1998; 112: 379-386.

80. Waddell J, Morris RW, Bouton ME. Effects of bed nucleus of the stria terminalis lesions on conditioned anxiety: aversive conditioning with long-duration conditional stimuli and reinstatement of extinguished fear. Behav Neurosci 2006; 120: 324-336.

81. Walker DL, Miles LA, Davis M. Selective participation of the bed nucleus of the stria terminalis and CRF in sustained anxiety-like versus phasic fear-like responses. Prog Neuropsychopharmacol Biol Psychiatry 2009; 33: 1291-1308.

82. Duvarci S, Bauer EP, Pare D. The bed nucleus of the stria terminalis mediates interindividual variations in anxiety and fear. J Neurosci 2009; 29: 10357-10361.

83. Resstel LB, Alves FH, Reis DG, Crestani CC, Correa FM, Guimaraes FS. Anxiolytic-like effects induced by acute reversible inactivation of the bed nucleus of stria terminalis. Neuroscience 2008; 154: 869-876.

84. Guo JD, Hammack SE, Hazra R, Levita L, Rainnie DG. Bi-directional modulation of bed nucleus of stria terminalis neurons by 5-HT: molecular expression and functional properties of excitatory 5-HT receptor subtypes. Neuroscience 2009; 164: 1776-1793.

85. Bagdy G, Graf M, Anheuer ZE, Modos EA, Kantor S. Anxiety-like effects induced by acute fluoxetine, sertraline or m-CPP treatment are reversed by pretreatment with the $5-\mathrm{HT} 2 \mathrm{C}$ receptor antagonist SB-242084 but not the 5-HT1A receptor antagonist WAY-100635. Int $\mathrm{J}$ Neuropsychopharmacol 2001; 4: 399-408.

86. Singewald N, Salchner P, Sharp T. Induction of c-Fos expression in specific areas of the fear circuitry in rat forebrain by anxiogenic drugs. Biol Psychiatry 2003; 53: 275-283.

87. Ciocchi S, Herry C, Grenier F, Wolff SB, Letzkus JJ, Vlachos I et al. Encoding of conditioned fear in central amygdala inhibitory circuits. Nature 2010; 468: 277-282.

Translational Psychiatry is an open-access journal published by Nature Publishing Group. This work is licensed under the Creative Commons Attribution-NonCommercial-No Derivative Works 3.0 Unported License. To view a copy of this license, visit http://creativecommons.org/licenses/by-nc-nd/3.0/

\section{Supplementary Information accompanies the paper on the Translational Psychiatry website (http://www.nature.com/tp)}

